\title{
NOTA EXPLICATIVA
}

\section{UM ARQUIVO DE PESQUISA}

\section{EDUARDO COSTA}

Universidade Estadual de Campinas (Unicamp), Campinas, São Paulo, Brasil

Pós-doutorando no Instituto de Filosofia e Ciências Humanas-Unicamp, onde também defendeu mestrado e doutorado. Graduado em arquitetura pela Unicamp. Doutoradosanduíche na Universidade de Coimbra, Portugal (2011-2012). Foi professor de história da arquitetura na Escola da Cidade. Vencedor do XI Prêmio Funarte Marc Ferrez de Fotografia, em 2010, e do ProAC/14 em 2009, da Secretaria de Estado da Cultura do Governo de São Paulo.

RECEBIDO

$26 / 10 / 2015$

DOI

APROVADO

http://dx.doi.org/10.11606/issn.1980-4466.v0i20p216-220
02/12/2015 
Em agosto de 2013, fui convidado pelo Centro de Preservação Cultural da Universidade de São Paulo (CPC-USP) para realizar uma documentação fotográfica dos bens da USP já tombados ou em processo de tombamento. Essa solicitação tinha objetivos claros, que seriam incluir novos documentos visuais ao arquivo da instituição, contribuindo, assim, para a formação de um conjunto documental que pudesse revelar novos aspectos ou, ainda, destacar elementos conhecidos em sua atual condição. No que se refere aos bens ainda não tombados ou em processo de tombamento, esse trabalho teve como objetivo produzir documentos visuais que possam contribuir com reflexões e debates sobre as características formais dos bens em questão. Trata-se, portanto, de um conjunto de fotografias com fins documentais, ligado especialmente à reflexão patrimonial da USP.

Essa iniciativa merece ser destacada dentro de uma política de preservação moderna, na qual os arquivos fotográficos assumiram papel de destaque, desde o final do século XIX. Se podemos identificar a proeminência da fotografia nos primeiros manifestos ligados à preservação, é no século XX que a fotografia viria a assumir um lugar de destaque na sua relação com o patrimônio e os processos de tombamento. Neste sentido, pode-se destacar o papel assumido pela fotografia no interior do Instituto do Patrimônio Histórico e Artístico Nacional (Iphan) e de outras instituições brasileiras, revelando a singularidade deste suporte documental para a consolidação da política nacional, além da 
manutenção de um lugar para o Brasil em contexto internacional.

Essas características me parecem importantes de serem identificadas e destacadas nesta nota, visto que não sou fotógrafo por formação e não desenvolvo, portanto, uma fotografia autoral, condição esta que ganhou lugar de destaque na trajetória recente da fotografia e encontra desdobramentos importantes sobre a compreensão do patrimônio brasileiro. Vale destacar que meu percurso acadêmico está intimamente relacionado a uma cultura visual patrimonial e arquitetônica em que a fotografia cumpre importante papel na organização de narrativas, discursos e sentidos para a arquitetura e a história da preservação. Neste sentido, ao longo de minhas pesquisas acabei por me dedicar paralelamente à prática documental da fotografia, e pude assimilar e refletir sobre limites, dificuldades e potencialidades do suporte fotográfico na representação e preservação do patrimônio. As fotografias agora arquivadas e preservadas pelo CPC-USP são, portanto, fruto dessa investigação acadêmica e resultado de uma reflexão científica em que se destacam as características documentais da fotografia.

Foi por meio dessa minha reflexão acadêmica que fui convidado para realizar a documentação de variados aspectos de 18 edifícios ou conjuntos construídos: Faculdade de Arquitetura e Urbanismo; Centro Universitário Maria Antônia; Faculdade de Medicina; Faculdade de Direito; Museu Paulista; Museu de Zoologia; Museu Republicano; edifício da História da Faculdade de Filosofia e Ciências Humanas; edifícios da Mecânica, Metalurgia e Minas e Energias da Politécnica; os prédios da Reitoria, Praça do Relógio e Conjunto Residencial da USP (Crusp) da Cidade Universitária; Centro de Práticas Esportivas da USP; alguns edifícios do campus de São Carlos e de Pirassununga; Engenho dos Erasmos; Casa de Dona Yayá; Instituto de Astronomia, Geofísica e Ciências Atmosféricas.

Destaco que esse conjunto documental é também fruto de um estreito diálogo com o CPC-USP, uma vez que me foi solicitada a documentação de aspectos particulares desses bens, como revelam algumas das instruções indicadas nas legendas das fotografias a seguir.

Essas legendas não pretendem expor a complexidade de relações que se organizaram para a feitura de tal arquivo, o que poderia revelar um trabalho de escolha de representações, luminosidades, o diálogo com os diretores das instituições envolvidas e tantos outros aspectos. Trata-se, no 
entanto, de sinalizar para um conjunto documental que prescinde de um fotógrafo, mas também das ideias que regem a instituição. Se fotografar é um ato de escolha, é fundamental identificar quais são os autores e as intenções por trás das imagens pertencentes aos arquivos, especialmente quando se trata de um arquivo destinado à preservação do patrimônio. Espera-se, assim, que este arquivo não seja uma mera ilustração deste patrimônio ou apenas uma representação dos conjuntos retratados, mas que seja um instrumento de pesquisa em seu sentido amplo.

FIGURA 1

Fachadas, registrando o estado atual -

Museu Paulista.

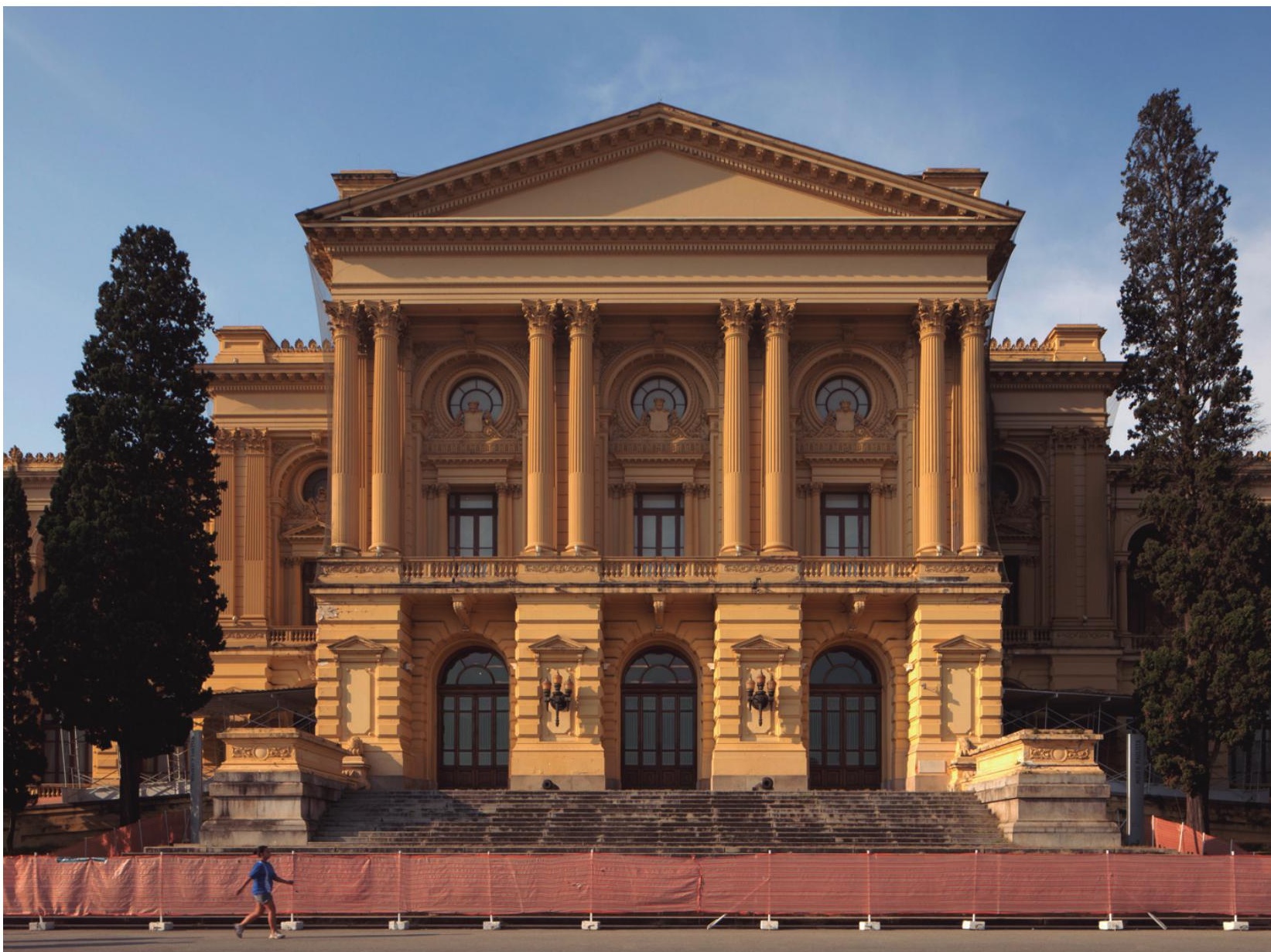


FIGURA 2

Detalhe dos elementos vazados - Edi-

fício da Mecânica /

POLI-USP.
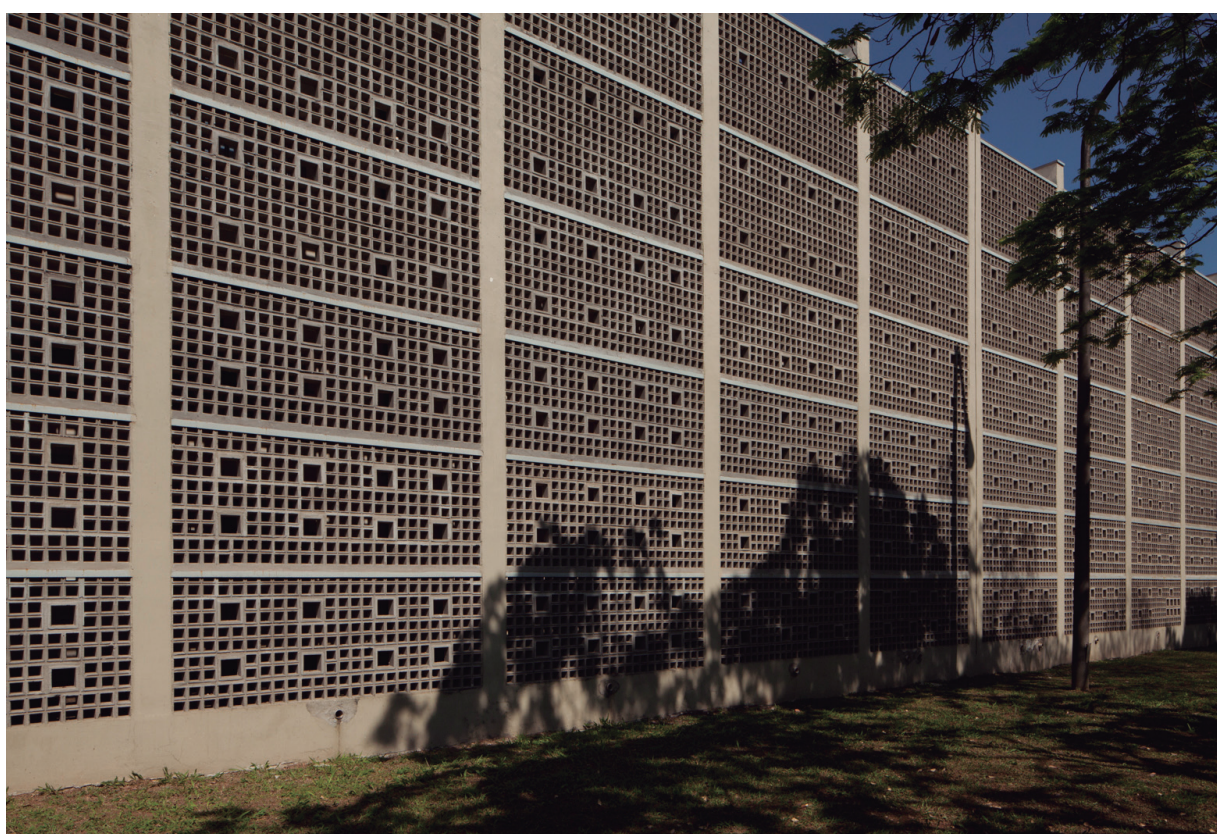

FIGURA 3

Perspectiva da Praça do Relógio - Praça do Relógio / Cidade Universitária.

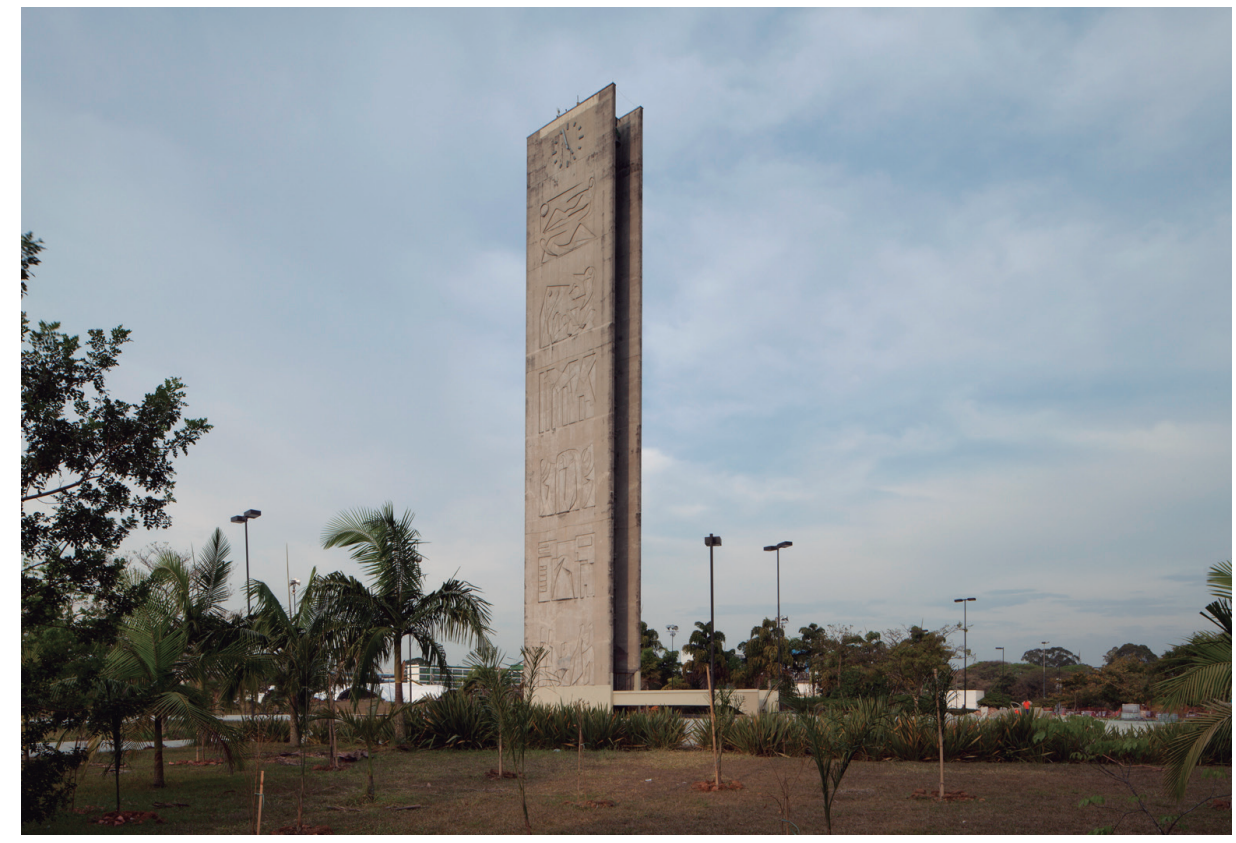

